\title{
GEO-ERÓTICA: CORPORIZACIONES DEL TERRITORIO EN EL CRIOLLISMO CHILENO
}

\author{
GEO-ERÓTICA: EMBODINGS OF TERRITORY IN CHILEAN CRIOLLISMO
}

\author{
Mario Verdugo Arellano \\ Universidad de Talca. Talca, Chile \\ verdugoarellano@gmail.com
}

Recibido: 02.01.2014. Aceptado: 04.04.2014.

Resumen: Este artículo examina las imbricaciones de espacio y sexualidad durante el auge criollista, apuntando la persistencia de un modelo axiológico cuyo efecto es la verticalización del par centro-periferia. Capaz de imponerse a otros criterios clasificatorios, como la raza, el género y la clase social, el "geoestatus" domina la perspectiva de autores y agentes diegéticos, amén de avenirse con los propósitos de exhibición, expansión y extracción nacionalizantes. El orden que prescribe los encuentros entre metrópolis y tierras vírgenes, o entre provincianos y afuerinos, viene a ser reinscrito dentro de un proceso cultural heterogéneo al que se designa como "ficción territorial".

Palabras clave: Territorio, criollismo, hinterland, literatura regional, geo-erótica.

\begin{abstract}
The article examines the imbrications of space and sexuality during the criollista peak, pointing to the persistence of an axiological model whose effect is upright the couple center-periphery. Capable of imposing in front of other classification criteria -as race, gender and social class- "geo-status" controls the perspective of authors and diegetic agents, to reconcile with purposes of exhibition, expansion and extraction of the nation. The order which determines the contacts between metropolis and wilderness, or between natives and outsiders, is reintroduced in a cultural and heterogeneous process, suggested to call territorial fiction.
\end{abstract}

Key words: Territory, criollismo, hinterland, regional literature, geo-erótica. 


\section{Introducción}

L Criollismo, de acuerdo a nuestra propuesta, puede inscribirse como el
primer momento institucionalizado de aquel proceso heterogéneo en el que se construyen y reconstruyen discursivamente los espacios no centrales de Chile. Dicho proceso, al que sugerimos llamar ficción territorial, va mostrando que las periferias, las provincias o las regiones distan mucho de corresponderse con esas categorías estáticas, inmutables, sustraídas al devenir histórico, que de costumbre suscriben tanto descriptores como metadescriptores, tanto personajes como críticos y autores en sus documentos autorreflexivos.

Inaugurada acaso por el criollismo, la ficción territorial se prolonga desde el medio siglo con la emergencia de la poesía lárica, extendiéndose más tarde en virtud de la variante regionalista surgida junto al proyecto dictatorial de regionalización. Sin perjuicio de que se detecten otras interpretaciones modélicas, el examen del proceso referido permite identificar estos tres espaciamientos dominantes, con frecuencia contenidos dentro de las nominaciones que han ido planteándose al respecto y a menudo encadenados por medio de intertextos y metatextos ${ }^{1}$. Cada modelo toma así su "apellido" de ciertas matrices designativas presentes en la crítica chilena, aunque ninguno alcanza a calzar punto por punto con cada una de ellas, importándonos únicamente aquello que se vincula con la tematización de los espacios periféricos en el ámbito subnacional.

Vigente durante un lapso algo mayor del que suele concederse al "criollismo" en general, el primer segmento de la ficción territorial se desarrolla a partir de tres operaciones características: función monádica, ampliación del ecúmene y explotación del hinterland. Merced a tales procedimientos, la periferia aparece como un espacio que se exhibe, que se expande y del

\footnotetext{
${ }^{1}$ Durante las décadas del 50 y el 6o, por ejemplo, la literatura criollista resulta torpedeada por una formación que, en palabras de Claudio Giaconi (1977 [1958]): 370), busca sustituirla por la "apertura [hacia una] mayor universalidad" y desacreditarla en función de sus "limitaciones geográficas", aunque no es sino con la tentativa canonizadora de Jorge Teillier en Los poetas de los lares cuando la ficción territorial adquiere continuidad, puesto que el programa lárico comporta menos un demérito del tema que un regreso a él empleando otras herramientas, en cualquier caso alejadas de la "poesía descriptiva" y de la "mera enumeración naturalista que conduciría a una especie de criollismo poético" (Teillier, 1965: 23).
} 
que se extraen insumos de toda especie. Los "rincones" quedan definidos por su lazo sinecdóquico y heterónomo respecto del todo nacional, lo que se refrenda al interior de las propias novelas y de los propios poemas pero más frecuentemente a través de paratextos chilenizantes. La relación entre Chile y sus periferias conlleva además la intervención de un tercer actor, cuyas maniobras a veces desembozadas y a veces tácitas colorean las categorizaciones del estatus geográfico ${ }^{2}$. Ese actor es desde luego el núcleo geopolítico, aquel punto prestigioso que goza del privilegio de abarcar, penetrar y dar forma; el eje desde donde se emprenden las actividades de exhibición y expansión. Los territorios mostrados e incorporados requieren lógicamente de un enfoque. El afuera contradictorio en que se sitúan los rincones reclama un adentro ya chilenizado en el cual se acopiarán las imágenes. De allí se sale en pos de tierras vírgenes y allí se llega con las fortunas recogidas.

Multiforme y pegadiza, la preponderancia del centro se grafica de modo notable en los acontecimientos narrativos que tematizan al amor y la sexualidad. Dones como el atractivo y la potencia son efectivamente condicionados por los lugares en que se nace o se reside, por las ciudades que se añoran o por las aldeas que se vilipendian, por el estatus geográfico en definitiva. Algunas formas de tal condicionamiento, y en particular las que se asocian con la provisionalidad de las conductas ${ }^{3}$, constituyen el tema de los siguientes párrafos.

${ }^{2}$ Con geoestatus o estatus geográfico aludimos a un persistente ordenamiento que se singulariza por la hipervaloración del centro y la minusvaloración de la periferia dentro de un contexto intranacional. El efecto más sobresaliente del geoestatus es la verticalización axiológica del par centro-periferia, de modo que el primer término de la relación queda ubicado también "arriba". Bajo tal modelo, los hechos narrativos suelen restringirse a una mera cuestión de ascensos, descensos y estancamientos.

${ }^{3}$ Entre las manifestaciones comunes de la explotación del hinterland se encuentra precisamente la provisionalidad ligada a ciertas faenas mineras. Quien se apersona en la periferia, dentro y fuera de las historias, como escritor o como personaje, lo hace con una limitación temporal y sin el deseo de establecerse. Es, en tales casos, alguien que llega motivado por una expectativa de usufructo, aunque no siempre esa expectativa quede satisfecha y aunque no sea siempre de carácter económico. Se buscan provisiones y se está ahí -al menos en teoría- nada más que por un tiempo. Con frecuencia, los forasteros conservan incólumes sus bases apriorísticas, su superioridad respecto del entorno provisional, mientras que los nativos resultan esquilmados, abandonados o degradados. 


\section{Elite erótica e indigencia sexual}

En Mercedes Urízar (1973 [1934]), de Luis Durand, la monótona existencia provinciana en que ha vivido la heroína funge como prolegómeno al arribo de Andrés García a Villa Hermosa. La peculiar complexión de este personaje femenino actúa como un imán para el forastero, quien por su parte ve en ella un horizonte de "promesas infinitas" (59). La imagen de Mercedes, no obstante, adquiere características naturalizadoras e inmovilizadoras, a las cuales se pliega la dinámica autoexposición del sujeto metropolitano que fluye en el discurso indirecto libre. Mientras García ama con el objetivo, consciente o no, de amortiguar la caída de su rango al instalarse como preceptor de provincia, Mercedes se entrega a la oportunidad de irse "de aquel pueblo que se le hiciera odioso", con rumbo "a una ciudad grande, donde ella le ayudaría a buscar otros senderos más propicios" (307). El amor de García corresponde entonces a la idealización compensatoria del espacio estancado, y el de Mercedes a la aspiración ahora viable de cesar su relación vicarial con el espacio-tiempo prestigioso ${ }^{4}$.

Un retrato inicial laudatorio, parecido al de la heroína de Durand, es el que comparten las protagonistas de Cecilia (1985 [1907]) y La señorita Cortés Monroy (1928), ambas novelas de Januario Espinosa. Estas mujeres excepcionales operan como fuerzas gatilladoras de las huidas masculinas, de modo que el despertar erótico puede leerse como contemporáneo del impulso por escapar del sedentarismo aldeano. Peculiar hechura poseen, en una y otra novela, los enamorados en lo que respecta a sus datos de lugar. Benito Valenzuela, hasta antes de su exitosa reconversión de acuerdo a los parámetros capitalinos, ha sido criado en Rari y por ende es coterráneo de Cecilia, en tanto que José María Negrete ha llegado a la capital provincial desde un conglomerado todavía menor, por lo cual su desplazamiento connota una línea ascendente, como peldaño intermedio de una futura emigración al centro del país. José María y Benito medran del prestigio que les confiere su papel de afuerinos funcionales, el primero como provinciano

${ }^{4}$ En buena parte de los relatos aquí estudiados, el vínculo con la metrópoli es también un vicariato, manifestado como ensueño compensatorio, como una conciencia admirativa o como un deseo de centro que prohíbe la negociación entre identidades y que a veces desemboca en una trabajosa resocialización. 
en ascenso, el segundo como reambientado en Santiago. Al final las dos parejas se rompen por el mismo motivo, que no es otro que la caducidad del aporte que las nimbadas mujeres de pueblo pueden hacer al proceso de cambio. Las heroínas, una vez que han propulsado la emigración, pueden desecharse como una carga molesta, y devolverse a la corrupta inmovilidad del espacio periférico.

En Charca en la selva (1962 [1934]), de Fernando Santiván, Adelaida reactualiza un esquema que María Teresa Zubiaurre ha estudiado en la novela decimonónica: aquella separación entre un espacio masculino abierto y un espacio femenino cerrado, los que al entrar en contacto se traducen en el vínculo asimétrico entre un "personaje-ventana" ("el forastero envuelto en un aroma de aventura") y una "mujer-inserta" cuya inactividad resulta remecida por la llamativa extranjería a la que se enfrenta (Zubiaurre, 2000: 29-30). Reiterado más allá del realismo francés del diecinueve, este esquema se enlaza además con un viejo cliché literario, aquel "según el cual la potencia colonizadora masculinamente se aprovecha de la femenina debilidad del continente colonizado" (Zubiaurre, 2007: 336). La esposa del ingeniero Casals entra en escena victimizada por el tedio, y previsiblemente se dinamiza por medio del forastero Franco Linares, a quien el mercado erótico del pueblecito de X no le prodiga a su llegada atracciones de fuste. La introducción de una espacialidad de cuño mundonovista en Charca en la selva se exterioriza en el primitivismo zoomórfico del Macho Préndez, amante ocasional de Adelaida, pero pronto desechado como "un perro al que se le da una migaja y luego se le manda cambiar de un puntapié" (154). Mario Casals, el marido burlado, experimenta las insuficiencias de su identidad periférica en la forma de un sentimiento de minusvalía cuya manifestación última será una escena de eyaculación precoz (206). Frente a la irrupción de Franco, tanto Préndez como Casals pierden toda opción de (re)conquistar a Adelaida, debiendo contentarse el segundo con un placer residual, dependiente de la interposición del santiaguino: aquella "sugestión satánica” que le ofrece el "cuerpo impuro" de su esposa, "todavía con las huellas de la fiebre de la carne que vibró y languideció en brazos de otro hombre" (205).

De Augusto D’Halmar es el cuento "En provincia” (1963 [1914]), donde se invierte la analogía hombre/dinamismo versus mujer/inmovilidad, manteniendo sin embargo el orden jerárquico que prioriza al centro en de- 
trimento de la periferia. Ello habla nuevamente de la especificidad de los problemas espaciales y de la torpeza que implicaría subsumirlos bajo categorías sexogenéricas, étnicas o socioclasistas. El periférico del cuento trabaja en un pequeño emporio, uno de los microespacios que Bajtín (1989) integra al catálogo del cronotopo provinciano ${ }^{5}$. Este empleado de comercio posee por cierto una dote atlética hiponormal ("gordo", "calvo", "fracasado", "un muerto que hojea su vida"), y eventualmente consigue acceder al piso inferior de un edificio en cuyos altos se aloja un matrimonio de la metrópoli. Sin perder la conciencia de su ridículo, el personaje se enamora de la capitalina, y si bien ésta accede a sus deseos, no tarda en denigrarlo y descartarlo. En primera instancia, la mujer expulsa a su galán de provincia, y luego la pareja regresa a Santiago, aun cuando ella ha sido inseminada al parecer por el empleado. De modo que el centro puede "bajar" y dejarse fecundar por la periferia, pero no unírsele pública ni permanentemente. La relación sigue siendo provisional, provechosa para quien se marcha y movilizadora para quien se queda: "iMujer enigmática! iJamás he comprendido qué fui para ella: capricho, juguete o instrumento! ${ }^{6}$.

\section{Territorios y cuerpos en la obra de Mariano Latorre}

Los textos de Latorre proporcionan múltiples ejemplos de amores moldeados por el geoestatus. En la Autobiografía de una vocación / Algunas pre-

${ }^{5}$ Escribe Bajtín, a propósito de este cronotopo menor modelizado por Flaubert: "Aquí no existen acontecimientos. El tiempo carece de curso histórico ascendente [...] La gente come, bebe, tiene esposas, amantes (sin amor), intrigan mezquinamente, permanecen en sus tiendecitas y en sus despachos, juegan a las cartas, chismorrean" (Bajtín, 1989: 388).

${ }^{6}$ Hay más casos, siquiera parciales, de esta inversión de los roles sexogenéricos como encarnaciones antonomásticas del espacio. En Pueblecito (1937 [1917]), comedia de Armando Moock, Marta vuelve al pueblo de su infancia llevando consigo "la maldita coquetería de la ciudad" (111). Su visión de la vida santiaguina es bastante crítica, y la de la provincia algo idealizada, pero de todas maneras despierta el amor en los varones de la comarca y la envidia entre las aldeanas, hastiadas de una existencia que se consume "en este pueblo que odiamos" (58). Más evidente resulta la provisionalidad de la estadía en María Nadie (1997 [1957]), de Marta Brunet. Aquí es una mujer forastera la que viene a dinamizar a los hombres del pueblo de Colloco. María aprovecha su tiempo en el pueblo para efectuar una especie de introspección, extrayendo provisiones "espirituales” y marchándose enseguida. 
guntas que no me han hecho sobre el Criollismo (1953), inclusive, hay un pasaje donde el dominio geoerótico se nacionaliza, convirtiendo al territorio chileno en un cuerpo que se ha aprendido a querer con apasionamientos y recelos. La isla de los pájaros (1955) muestra a un profesor de Santiago entablando "amoríos tan sólo carnales" con Chella, la chilota adolescente que refleja en su fisonomía el primitivismo de la isla. Se trata, igual que tantas otras veces, de una relación transitoria, sostenida apenas por el lapso que dura el año escolar, y que suele consumarse a la intemperie, reforzando ante el pensamiento del santiaguino los estereotipos naturalizantes que hacen presa del rincón. Zurzulita (1960 [1920]) presenta a primera vista situaciones muy semejantes. Milla es casi un personaje sinónimo de Chella. La hija del ciego Aravena aparece como "el alma de aquel rincón abrupto", "terroncito gris, chillido huidizo de pájaro" (256). Pero de Milla, si se la compara con Chella, se entregan muchos más pormenores prosopográficos y etopéyicos. El discurso narratorial suma complejidades que se engarzan con las resistencias típicas del mundonovismo. Hay, en realidad, más de una Milla: la que transforma una estancia repugnante en topofilia, la que es percibida como excepción dentro del deterioro general, la que sintetiza la bestialidad del entorno y, por último, la que malogra los afanes del "pijecito" Elorduy y que prefiere quedarse en Millavoro, rechazando las ofertas matrimoniales del afuerino que acaba de fecundarla (296-297)7.

Lector de Pérez Rosales y pintor de paisajes aún inaprensibles para "la paciencia de la Kodak" (34), Emilio Labarga encuentra en el sur una geografía erotizada por partida doble: la virginidad del espacio y la virginidad de Ully (1968 [1923]), figura antonomástica del hinterland explotable. En la nouvelle de Latorre, la mujer-inserta es la joven nieta de un emigrante bávaro, una "linda chiquitina" que asoma como "algo vaporoso, alado" (15). Hacia la caracterización de esta "graciosa figurita" convergen, por un lado, los atributos de inocencia y de lubricidad que el discurso imperial asigna a los territorios periféricos; y por otro, los factores tanto raciales como espaciales que determinan las taxonomías humanas. La descendiente de

${ }^{7}$ Como afirman Shohat y Stam (2002), las ficciones eróticas del colonialismo oscilan entre la virginidad edénica (disponible) y la peligrosidad infernal (domable). La imagen de Zurzulita fluctúa también entre ambos polos, aunque al fin y al cabo triunfa la femineidad violenta y salvaje. 
colonos prodiga gestos "puros" pero también "picarescos" y "provocativos" (37). A Labarga lo estimulan a la vez la "pantorrilla virgen" de Ully (24) y el paisaje con su "bosque virgen" y su "selva virgen" (77). Los espacios reclaman una elaboración pictórica y la muchacha pide ser mondada y mordida como si realmente se tratase de una manzana del huerto (57). Ully no vale sólo por su raza ("el tipo refinado de la rubia", 15), sino además por las contradictorias sugestiones que el ambiente sureño ha impuesto a su cuerpo y a sus deseos: la acción vivificante tan típica del mundonovismo y la conciencia admirativa que el centro despierta por igual entre las provincianas de todo Chile (38). Bajo tales condicionamientos, la relación amorosa tendrá de nuevo un sesgo provisional y las jerarquías espaciales se verán reafirmadas aun cuando pareciera que se las estuviese cuestionando. El sur comporta, en resumen, un remanso de vitalidad, rehuido justo antes de que se convierta en charca ${ }^{8}$.

\section{Sementales afuerinos y mujeres insertas}

El descarte de Ully ejemplifica la existencia de un criterio espacializado para clasificar y discriminar posibles amantes. El centro y la periferia se corporizan en una desigual distribución del capital erótico, generando un conjunto de imágenes estandarizadas que no se restringen a una mera cuestión de pigmentos o de genes. De otra manera sería difícil entender que Labarga prescinda de una "alemancita" que cuadra perfectamente con su imaginario racista. Por sus rasgos blancos, germanos, europeos, Ully es atractiva y deseable, pero por vivir en provincia, por la impregnación metonímica del entorno, no sirve para una unión duradera. El binarismo de este esquema permite no obstante una gama amplia de variaciones. Si todo tópico se perpetúa a partir de flexibles remozamientos (López Martínez,

${ }^{8}$ Charca en la selva es, de hecho, el título de la novela de Fernando Santiván donde el inmóvil pueblecito de " $\mathrm{X}$ " se ha convertido precisamente en un espacio estancado y corrupto. En todas o casi todas las imágenes examinadas en el presente artículo, la periferia territorial es un espacio que no se mueve, y en todas o casi todas esa carencia de movimiento se juzga como algo deplorable, como una charca que corrompe a los personajes. Refiriéndose a la novelística de Januario Espinosa, Raúl Silva Castro (1928: 428) destacaría la habilidad del narrador para asomarse "largas horas al pozo nauseabundo: la provincia donde se pudren los deseos". 
2007), las estabilidades subnacionales no son la excepción. Así, los forasteros inseminadores pueden ser descritos como buenos o malos, bondadosos o mezquinos, omnipotentes o endebles, aunque en la totalidad de los casos su origen espacial implica cierta idea de privilegio. En "El pueblo muerto" (1976 [1935]), Pedro Prado pone a Juan Otamendi frente a una aldeana que "no [le] despega los ojos", una aldeana que carece de cualidades raciales, que es "deslavazada y descolorida", y cuya "mirada insistente" semeja "el vuelo de un insecto desagradable" (59). En la novela Pueblo chico (1932) de Manuel Ortiz, el forastero es un sacerdote de Santiago que se establece como párroco de Villabaja, en busca de feligreses todavía no corrompidos por la gran urbe. La belleza natural de Villabaja y sus alrededores contrasta sin embargo con "las villanías" de la población autóctona, y especialmente con los vicios de los "Alarcones" y los "Albornoces", familias nativas enemistadas con los grupos mucho más cultos que han llegado a la aldea en fecha posterior. Por cierto que el párroco se enamora de una advenediza, la virginal Emilia, y aunque ésta mantiene una distancia casta, imponiéndose la honestidad del sentimiento por sobre las trabas del celibato y el sacrilegio, a la postre será la asechanza de los locales lo que arruinará el enlace, de modo que Emilia muere a causa de la ignominia y el párroco termina subido a un árbol, completamente trastornado.

Esta configuración del forastero se invierte siquiera de forma parcial en Montaña adentro (1923), de Marta Brunet, donde los sujetos-ventana se diversifican en retratos elogiosos y reprobatorios. En lugar del metropolitano de competencias magnificadas, lo que hay aquí es una serie de "fuerinos" (sic) por lo general pobres, trabajadores temporeros que se instalan en las inmediaciones del volcán Llaima. Para Catita, la protagonista, existen claras diferencias entre ellos. En un extremo está Pereira, un carrilano de facciones "talladas en ámbar" (93) aunque proclive a las conductas violentas y a la "palabrería vana" (86); y en el otro Juan Oses, un peón que muestra signos de pertenecer -como informa el narrador- a una clase "afinada por la cultura” y aún inmune a la deformación del trabajo. Es Pereira quien embaraza a Catita, pero Oses el que la enamora y le ofrece matrimonio. Tras enterarse de esta oferta, Pereira asesina a su rival, espoleado por la envidia que le provoca el ser vencido por un "hijo de rico" (42).

Las mujeres-insertas también presentan una apreciable riqueza tipológica, si bien persiste su posición desmedrada dentro del estatus geográfi- 
co. Junto a peligrosas heroínas mundonovistas como Zurzulita, aparecen vírgenes como Ully, o lugareñas aburridas como las de Charca en la selva o La Hechizada (1916), otro relato de Fernando Santiván. De nombre "Humilde", esta última joven capea el hastío del fundo Las Pataguas pensando en "otra parte", en el movimiento de la ciudad, en los romances vicariales que el campo entorpece con su "rezongo monótono" (11). Ante Baltasar, el forastero de rigor, los ámbitos campesinos cobran pese a todo un cariz idílico, coincidente con la tópica del locus amoenus. Pero el proyecto se frustra por los atavismos y las lacras medioambientales que más tarde se develan con total franqueza: Humilde ya tiene novio, y ese novio no es otro que su primo Saúl. La viciosa endogamia es el factor que vuelve a separar los mundos y que expulsa finalmente a Baltasar en una escena no exenta de sollozos y alaridos. Santiván reiteraría el repudio de estas prácticas endogámicas en Escuelas rurales. Para colonos montañeses y pequeños propietarios (1933), ahora de manera más directa. A juicio del autor, la sexualidad de los colonos y los indígenas se halla marcada por la barbarie del medio. Sus costumbres promiscuas "engendran precoces concupiscencias" y suscitan "mezclas diabólicas de sangres familiares que acrecen en forma siniestra la natalidad de [retrasados]" (37). A la espera de la redención nacionalizante, que habrá de "feminizar" unos hogares necesitados de "flores" y de "adornos", las mujeres campesinas asquean a Santiván con su desaliño y con el caos de sus ranchos "incultos" y "mugrientos" (131).

\section{Geopolítica y geofilia}

Los fenómenos geoeróticos no se supeditan únicamente al comercio carnal entre actores afuerinos y nativos. Tierra en celo (1946), novela de Juan Donoso, ratifica la continuidad de los modelamientos espaciales aun cuando la periferia se halle libre de intrusiones y seducciones foráneas. El hinterland puede sexualizarse de por sí, en razón de sus propias rutinas, antes de que alguien llegue a él para exhibirlo, integrarlo, desflorarlo y explotarlo. Ello sin obviar que su tematización sigue obedeciendo a una forastería reconocible en a lo menos dos niveles: el de la perspectiva centralista del narrador y el del paratexto nacionalizante acá superpuesto por el editor Nicomedes Guzmán. En Tierra en celo el paisaje sufre aquel proceso de 
erotización que Alain Roger ha estudiado en la obra de Proust, Zola, Huysmans y Coleridge (Roger, 2007: 178-194). Juan Donoso otorga al relieve y a la flora regional connotaciones antropomórficas, y a la inversa aprovecha lo que Roger llama "reversibilidad metafórica" para insistir en el geomorfismo de hembras y de machos. Sin que se haya apersonado el centro seductor, los amantes de la novela se entregan a prácticas entre geofílicas y masturbatorias, que ciertamente hablan de la libidinosidad inherente al espacio: Damián y Elías, los hijos mayores de Doña Maiga, vuelven sus manos "contra esa piel espesa, deshaciendo los terrones y sobando las hierbas en una delectación morbosa de vellosidades íntimas" (52). El campo es visto como esencialmente voluptuoso y no hay deseo ni cópula que ahorre alusiones a elementos paisajísticos como el rumor del río, el sabor del trigo o el sol que quema los muslos y las nalgas. A veces estos tropos se ligan a coacciones de tipo social (el derecho de pernada ejercido por los propietarios), y en general vienen mediados por un falocentrismo a ultranza. Doña Maiga confirma ambos solapamientos con su racconto del episodio en que el Compadre Deme desflora a Dorila Yáñez, añadiéndole además los datos de una endogamia acá especificada lisa y llanamente como incesto (30-50).

La representación sicalíptica del campo chileno recrudece en otros géneros y en otros períodos, lo que equivale a decir que no constituye una rareza de la narrativa criollista. Ya en la década del 80, por ejemplo, Cristián Huneeus publica El verano del ganadero (2010 [1983]), una novela "pornográfica" que transcurre en predios del Cajón del Maipo y del interior de Teno. Por los años de Latorre, la asociación de erotismo y paisaje rural tiene una versión poética en las Baladas criollas (1940) de Carlos Acuña, donde proliferan las reyertas amatorias entre patrones impúdicos y risueñas reinas de la vendimia. Pero siendo un tópico capaz de trascender barreras epocales y genéricas, la representación en escrutinio parece avenirse de modo particularmente intenso con las operaciones extractivas del espaciamiento nacional. El rincón suministra recursos económicos e icónicos, pero también carnales. La disponibilidad de los territorios internos atrae tanto a los ojos como a los falos del núcleo geopolítico, y éstos penetran y colonizan seduciendo o violando. Si en un plano los sujetos periféricos aceptan sin reparos el fideicomiso afuerino, en otro acogen y reverencian como si configurasen un harén. Frontera (1949), de Luis Durand, es un texto prototípico en tal sentido. Anselmo Mendoza no encuentra grandes 
obstáculos ni en el ambiente ni en su propia conciencia para subyugar miríadas de tierras y de cuerpos. Para él, como para el narrador omnisciente, la región fronteriza es una zona virgen, carente de dueños, y las mujeres de la comarca se mantienen en un estado de constante excitación. El prontuario sexual de Don Anselmo incluye en primer término a su esposa Isabel, a quien "posee" sin esperar la boda, y en seguida acumula jóvenes oriundas, prostitutas traídas de más al norte, visitas ocasionales como la peruana Terencia Tagle, comerciantes casadas como Doña Emilia, y colonas rubicundas como Tusnelda Schindler. Mendoza está en el ápice de la élite erótica, conforme a la verticalización que el geoestatus impone al esquema centroperiferia, aunque eso no impide que en los puestos inferiores se dé curso a una especie de sicalipsis generalizada.

\section{Las pornotopías de Hernán Jaramillo 9}

Pero si Frontera exacerba las presuntas lujurias del hinterland, la obra de Hernán Jaramillo lleva dicha prescripción a su grado paroxístico. Lo que Latorre insinuara con su parca mención a un territorio-mujer, Jaramillo lo amplía en sus prólogos y ensayos: Chile es un cuerpo femenino, cuya transformación en literatura se identifica con un coito no precisamente consentido. Así lo expresa el autor, de forma enfática, en su Elogio de la china (1974 [1957]): "Abrazaré tu busto como si abrazara a Chile en la cintura por Coquimbo; besaré tu boca como si besara a Chile por Arica; restregaré entre las mías tus rodillas como si las hincara en Chile en Puerto Montt; juntaré mis pies a los tuyos como si pisara a Chile en Cabo de Hornos" (1974: 195). El trabajo de los escritores baqueanos ${ }^{10}$ redunda en una geografía nacional

${ }^{9}$ El término ha sido utilizado - para referir ciertas relaciones entre espacios y sexualidad-por Beatriz Preciado (2010).

${ }^{10}$ Bajo la férula del criollismo, el escritor es concebido repetidamente como un práctico de los caminos, un guía por las sinuosidades del hinterland. La incorporación de territorios tiene como avanzadilla a un elenco de cuentistas, poetas y novelistas que junto con guiar, entrega reportes sobre futuros beneficios. Cada obra literaria asoma como el resultado de una exploración ya consumada, pero que volverá a consumarse en el acto de la lectura. Los baqueanos, puesto que han estado ahí, son valorados como poseedores de una cierta experticia, a la que por lo demás se da un sentido patriótico. 
erotizada, y el rol de las regiones es el de incitar las apetencias de un telos chileno. El país y la china son objetos equivalentes, a un tiempo "bravíos" y "generosos", e igualmente localizables en los extramuros de la metrópoli. Puede advertirse que la perspectiva es también masculina, socialmente poderosa y pronta a desarrollar comportamientos coercitivos bajo la justificación del deber patriótico y de un incuestionado realismo mimético. De ahí que Chile sea "una tierra para viriles", no para esos "exquisitos que tienden, salvo raras excepciones, a la inhibición sexual o a la misoginia". A Jaramillo las hembras lo estremecen "como un potro alimentado con avena"; confesión que debe señalarse "con perdón de las damas pudibundas, menopáusicas de viejo cuño, de los linfáticos y los invertidos” (13).

Sobre tales bases monta Jaramillo su volumen de cuentos Los antojos de Deidamia (1952). La geoerótica subnacional es esta vez el eje de casi todas las historias. En el texto que da título al libro, una lugareña encinta apremia a su propio esposo, amenazándolo con abortar, para que consiga los servicios sexuales de un vecino. En "La docena de huevos", un pequeño cacique de Bullileo cambia vituallas por vírgenes con las que "entretener sus ocios y descargar las demasías de una naturaleza ardiente" (48). La figura del harén emerge de nuevo en "El quintal de harina", donde la progenie del acaudalado Pablo Bussow iguala o supera a su número de años (sesenta). Como una marca de ganado, el nombre de este afuerino va impreso en las telas de osnaburgo que las mujeres locales llevan como ropa interior.

En Los antojos... se reproduce la nacionalización del eros anunciada paratextualmente por el autor. Los huevos canjeados por la nubilidad de Rosalía Solorza son huevos chilenos, "magníficos", que "en ninguna otra parte el mundo" se pueden admirar (50). Y la trucha feminizada del relato final es una trucha "chilena por los cuatro costados de su descendencia", sin "contubernios extraños con salmonídeos importados" (221). Pero como se colige de otro cuento de este volumen, la relación entre las partes y el todo, entre los rincones y el país, entre las regiones y Chile, adquiere más de una vez el aspecto de un contrato leonino o, si se quiere, de una pasión en la que uno solo de los participantes obtiene ganancias. En "Ama de leche", un petimetre de Santiago llega a Cauquenes buscando recobrar sus decrecientes energías. El espacio es un "lugarejo", y allí no se echan en falta los minusválidos provincianos. Jorge Saldívar, el santiaguino, acierta sin embargo con el remedio para sus males: "un pecho que aparece espontáneo 
y dadivoso, un pecho abultado y morenusco, como una colina de secano" (203). Saldívar sorbe del cuerpo de Clarisa, y en apenas unos meses está listo para volver a la "tertulia" de la capital. El afuerino engorda y la nativa enflaquece; uno "se llena de ánimos" y la otra "se deshace de sus carnes como una olla de grasa junto al fuego" (208). Terminada la lactancia salutífera, Saldívar "arregla sus maletas", "escobilla el polvo de sus zapatos de ciudad", y se despide con "académica oratoria". La mujer se extingue y, como afirma el narrador, es como si el centro hubiese ido a devorar la crema del sustento a la campiña (209).

\section{Referencias}

Acuña, C. (1940). Baladas criollas. Santiago: Nascimento.

Bajtín, M. (1989). Las formas del tiempo y del cronotopo en la novela. Ensayos de poética histórica. Teoría y estética de la novela (pp. 237-409). Madrid: Taurus.

Brunet, M. (1923). Montaña adentro. Santiago: Nascimento. (1997 [1957]). María Nadie. Santiago: Pehuén.

D’Halmar, A. (1963 [1914]). En provincia. En Espinoza, E. (ed.), Antología de Augusto D'Halmar (pp. 95-106). Santiago: Zig-Zag.

Donoso, J. (1946). Tierra en celo. Santiago: Cultura.

Durand, L. (1949). Frontera. Santiago: Nascimento. (1973 [1934]). Mercedes Urízar. Santiago: Nascimento.

Espinosa, J. (1928). La señorita Cortés-Monroy. Santiago: Imprenta Universitaria.

(1985 [1907]). Cecilia. Santiago: Zig-Zag.

Giaconi, C. (1977 [1958]). Una experiencia literaria. En Promis, J. (ed.), Testimonios y documentos de la literatura chilena (1842-1975) (pp. 362-372). Santiago: Nascimento.

Huneeus, C. (2010 [1983]). El verano del ganadero. Santiago: Sangría.

Jaramillo, H. (1952). Los antojos de Deidamia. Santiago: Nascimento. (1974 [1957]). Elogio de la china. En Guzmán, N. (ed.), Autorretrato de Chile (pp. 193-196). Santiago: Zig-Zag.

Latorre, M. 1953. Autobiografía de una vocación / Algunas preguntas que no me han hecho sobre el Criollismo. Santiago: AUCH. (1955). La isla de los pájaros. Santiago: Nascimento. (1960 [1920]). Zurzulita. Santiago: Nascimento. 1968 [1923]). Ully. Santiago: Nascimento. 
López Martínez, M. I. (2007). El tópico literario: teoría y crítica. Madrid: Arco / Universidad de Extremadura.

Moock, A. (1937 [1917]). Pueblecito. En Teatro seleccionado (pp. 67-128). Santiago: Cultura.

Ortiz, M. (1932). Pueblo Chico. Santiago: Imprenta Universitaria.

Prado, P. (1976 [1935]). El pueblo muerto. En Montes, H. y Orlando, J. (eds.), Literatura regional de Chile (pp. 55-70). Santiago: Mar del Sur.

Preciado, B. (2010). Pornotopía. Arquitectura y sexualidad en "Playboy" durante la guerra fría. Barcelona: Anagrama.

Roger, A. (2007). Breve tratado del paisaje. Madrid: Biblioteca Nueva.

Santiván, F. (1916). La Hechizada. Santiago: Ediciones de Los Diez. (1933). Escuelas rurales. Para colonos montañeses y pequeños propietarios. Santiago: Imprenta Ercilla.

(1962 [1934]). Charca en la selva. En Camará / Charca en la selva (pp. 89-217). Santiago: Zig-Zag.

Shohat, E. y R. Stam. (2002). Multiculturalismo, cine y medios de comunicación. Barcelona: Paidós.

Silva Castro, R. (1928). La señorita Cortés Monroy, por Januario Espinosa. Atenea, $5,427-429$.

Teillier, J. (1965). Los poetas de los lares. Nueva visión de la realidad en la poesía chilena. Boletín de la Universidad de Chile, 56, 48-62.

Zubiaurre, M. T. (2000). El espacio en la novela realista. Paisajes, miniaturas, perspectivas. México: FCE. (2007). Ciudades rotas, urbes mecánicas, metrópolis de cartón: modernismo, vanguardia y poética de lo urbano en Manuel Díaz Rodríguez, Martín Adán y Arqueles Vela. En de Navascués, J. (ed.), La ciudad imaginaria (pp. 329-341). Madrid: Iberoamericana. 